OLIVEIRA, F.L.; RIBAS, R.G.T.; JUNQUEIRA, R.M.; PADOVAN, M.P.; GUERRA, J.G.M.; ALMEIDA, D.L.; RIBEIRO, R.L.D. Desempenho do consórcio entre repolho e rabanete com pré-cultivo de crotalária, sob manejo orgânico. Horticultura Brasileira, Brasília, v.23, n.2, p.184-188, abr-jun 2005.

\title{
Desempenho do consórcio entre repolho e rabanete com pré-cultivo de crotalária, sob manejo orgânico
}

\author{
Fábio Luiz de Oliveira'; Rodolfo Gustavo T. Ribas' Rodrigo M. Junqueira'; Milton P. Padovan²; José \\ Guilherme M. Guerra ${ }^{2}$; Dejair L. de Almeida ${ }^{2}$; Raul de L.Duarte Ribeiro ${ }^{1}$ \\ ${ }^{1}$ UFRRJ, Depto. Fitotecnia, BR 467, km. 47, 23890-000 Seropedica-RJ; E-mail: fabiocapi@ ufrrj.br; ${ }^{2}$ Embrapa Agrobiologia, C. Postal \\ 474505, 23890-000 Seropedica-RJ; E-mail: gmguerra@cnpab.embrapa.br
}

\section{RESUMO}

Foram conduzidos dois experimentos no Sistema Integrado de Produção Agroecológica, em Seropédica, (RJ), durante dois anos consecutivos. O objetivo foi avaliar o desempenho do consórcio entre as culturas de repolho e rabanete com pré-cultivo de crotalária, sob manejo orgânico. Usou-se delineamento experimental de blocos ao acaso com sete repetições, em parcelas subdivididas, representando um fatorial 2 × 3 , sendo o primeiro fator o pré-cultivo, com Crotalaria juncea e pousio (vegetação espontânea); e o segundo fator o sistema de cultivo (consórcio entre repolho e rabanete e os respectivos monocultivos). Não houve diferença significativa no tocante à produtividade do repolho ou rabanete, entre $C$. juncea e pousio, independentemente do tipo de manejo (monocultivos ou consórcio). O desenvolvimento do repolho não foi influenciado pela presença do rabanete, no consórcio entre essas espécies sob cultivo orgânico. O rabanete sob consórcio apresentou redução no diâmetro médio, massa média e produtividade de raízes, sem, contudo, desqualificar o padrão comercial das raízes colhidas. Considerando a média dos dois anos experimentais, o IEA atingiu 1,59, o que indicou a viabilidade do consórcio, otimizando práticas culturais, incluindo adubação, capina e irrigação.

Palavras-chave: Brassica oleracea var. capitata, Raphanus sativus, agroecologia, horticultura orgânica.

\begin{abstract}
Performance of cabbage and radish intercropping under organic management

Field experiments were carried out during two consecutive years in the Integrated Agroecological Production System, in Rio de Janeiro State, Brazil, to evaluate the performance of cabbage-radish intercropping under organic management on the basis of agronomic traits and Area Equivalency Index (AEI). The contribution of green manure pre-planting to the system also was evaluated. A randomized complete blocks design with seven replicates in a $2 \times 3$ split-plot factorial scheme was used. Treatments in the main plots consisted of Crotalaria juncea pre-planting or fallow. Cabbage or radish single crops and the respective intercropping were distributed in the subplots. No significant differences were detected between $C$. juncea and fallow as related to cabbage or radish yields in any of the systems used (single crops and intercropping). Intercropping had no effect on cabbage yield, but significantly reduced radish root yield. However, commercial standard of the harvested radish roots was not affected. An average AEI of 1,59 for the two experimental years was attained, thus indicating the viability of the cabbage-radish intercropping. The system makes possible to afford additional income for a given area cultivated with cabbage, at its conventional singlecrop spacing, by including radish as a secondary crop. Intercropping also was advantageous by allowing optimization of cultural practices such as fertilization, weeding, and irrigation.
\end{abstract}

Keywords: Brassica oleracea var. capitata, Raphanus sativus, agroecology, organic horticulture.

(Recebido para publicação em 15 de novembro de 2003 e aceito em 5 de janeiro de 2005)

$\mathrm{D}$ urante a última década, o nível de conscientização quanto às relações da agricultura com o ambiente, os recursos naturais e a qualidade dos alimentos cresceu substancialmente. Existe interesse entre os agricultores por sistemas alternativos de produção que aumentem a rentabilidade e melhorem a qualidade de vida no meio rural, além de preservar a capacidade produtiva do solo a longo prazo (EHLERS, 1999). Segundo Costa e Campanhola (1997), a adoção de práticas alternativas e conservacionistas de produção agropecuária, a par de atender aos anseios da sociedade por produtos que não degradem o ambiente em seu pro- cesso de obtenção, tende a se tornar um componente de competitividade no mercado, impulsionado pelas normas ISO14000 , que tratam da gestão ambiental das atividades produtivas.

Dentre as práticas alternativas de produção enquadram-se os consórcios de culturas, que antes da modernização e da industrialização da agricultura eram comuns, sendo o monocultivo a exceção. Em regiões tropicais, os consórcios permanecem amplamente utilizados (VANDERMEER, 1990), principalmente porque temperatura e radiação solar não se constituem em fatores limitantes durante quase todo o ano, bastando que haja disponibilidade de água (FAGERIA, 1989). As vantagens dos cultivos consorciados em relação aos monocultivos são o aumento da produção por unidade de área em determinado período de tempo, melhor distribuição temporal de renda, aproveitamento mais adequado dos recursos disponíveis, diversificação da produção, o que significa maior variedade de alimentos para as comunidades rurais, e menor risco de insucesso, além de conferir maior proteção ao solo (FAGERIA, 1989; VANDERMEER, 1990). Gonçalves (1981) ressaltou que os consórcios, por lidarem com diferentes ciclos de culturas, propiciam otimização da força de trabalho, safras mais elevadas e, 
consequentemente, maior rentabilidade para o produtor rural. Além disso, o consórcio entre plantas com diferentes ciclos e/ou portes reduz o crescimento de ervas espontâneas e a temperatura do solo, controla a erosão e otimiza o uso de insumos agrícolas (OLASANTAN et al., 1996).

Os estudos divulgados sobre consórcios, conduzidos na Baixada Fluminense, enfocaram, principalmente, sua eficiência em relação aos respectivos monocultivos (SUDO, 1998; PIMENTEL, 2001; OLIVEIRA, 2001; PAULA, 2003). Vários índices têm sido utilizados para essas comparações, dentre os quais o Índice de Equivalência de Área (IEA), que define a área sob monocultivo requerida para atingir as produtividades obtidas no consórcio (FAGERIA, 1989; VANDERMEER, 1990; SWIFT; ANDERSON, 1994).

Ressalta-se que os trabalhos envolvendo estudos de consórcios entre hortaliças são ainda escassos e apresentam amplas possibilidades. Oliveira (2001) relatou que a densidade de plantio da cultura do repolho, normalmente utilizada com média de 40 mil plantas ha ${ }^{-1}$, aliada à duração do seu ciclo, permite o cultivo consorciado com uma cultura de ciclo curto e que não produza muita folhagem, como é o caso do rabanete, otimizando o uso da terra e de insumos agrícolas.

Objetivou-se, neste trabalho, avaliar o desempenho agronômico do consórcio entre repolho (Brassica oleracea var. capitata) e rabanete (Raphanus sativus) sob manejo orgânico, bem como estimar a contribuição da adubação verde na produtividade dessas hortaliças.

\section{MATERIAL E MÉTODOS}

Foram instalados dois experimentos nos anos 2000 e 2001, no Sistema Integrado de Produção Agroecológica (SIPA), na região da Baixada Fluminense, em Seropédica, que vem sendo manejado com cultivo orgânico de hortaliças desde o ano 1993. O local apresenta altitude de $33 \mathrm{~m}$, temperatura média anual de $23^{\circ} \mathrm{C}$ e pluviosidade média anual de $1112 \mathrm{~mm}$, com período seco característico durante a estação de inverno.

Usou-se o arranjo em parcelas subdivididas, com os tratamentos pré-cul- tivo com crotalária (Crotalaria juncea) ou pousio (vegetação espontânea), compondo as parcelas, e o consórcio de repolho e rabanete, além dos respectivos monocultivos, compondo as subparcelas. O delineamento experimental foi blocos casualizados, com sete repetições.

O solo da área experimental foi classificado como Planossolo, série Ecologia, e os resultados da análise granulométrica e química de amostra composta retirada na profundidade de $0-0,20 \mathrm{~m}$ foram: argila $=830 \mathrm{~g} / \mathrm{kg}$; silte $=140 \mathrm{~g} / \mathrm{kg} ;$ areia $=30 \mathrm{~g} / \mathrm{kg}$ de solo $; \mathrm{pH}$ (água) $=5,5 ; \mathrm{Ca}^{++}=4,0 \mathrm{cmol} / \mathrm{dm}^{3} ; \mathrm{Mg}^{++}$ $=1,8 \mathrm{cmol} / \mathrm{dm}^{3} ; \mathrm{P}=200 \mathrm{mg} / \mathrm{dm}^{3} \mathrm{e} \mathrm{K}^{+}=$ $250 \mathrm{mg} / \mathrm{dm}^{3}$.

A crotalária foi semeada no espaçamento de $0,20 \mathrm{~m}$ entre linhas e na densidade de 30 sementes por metro de sulco. No primeiro ano de cultivo (2000), aos 92 dias após semeadura, quando em estádio de plena floração, foi roçada ao nível do solo, o mesmo acontecendo com a vegetação espontânea das parcelas em pousio. No segundo ano de cultivo (2001), essa prática foi realizada de forma semelhante, porém aos 120 dias após semeadura. A biomassa das plantas foi incorporada ao solo, com enxada rotativa, antecedendo o transplantio das mudas de repolho e semeadura direta do rabanete. Usou-se a cultivar de repolho Astrus, cujas mudas foram produzidas em bandejas de poliestireno expandido com 200 "células", com substrato orgânico formulado no local. O transplante foi feito aos 23 dias após o semeio, em canteiros de $1 \mathrm{~m}$ de largura, no espaçamento de 0,5 x 0,5 $\mathrm{m}$. No primeiro ano, procedeu-se à semeadura do rabanete cultivar Sakata $n^{\circ}$ 19, aos dez dias após o transplantio do repolho, no espaçamento de $0,25 \mathrm{~m}$ entre sulcos e 0,05 m entre plantas. Cada subparcela continha doze plantas de repolho, dispostas em duas fileiras de seis plantas no sentido do comprimento, e de 10 sulcos de rabanete, dispostos no sentido da largura do canteiro. Considerou-se como área útil aquela ocupada pelas quatro plantas centrais de repolho e/ou por quatro fileiras de rabanete.

Tanto no monocultivo como no cultivo consorciado, a densidade populacional de ambas as culturas foi a mesma. No segundo ano, o espaçamento foi mantido, porém a semeadura do rabanete foi realizada concomitantemente ao transplantio do repolho. No plantio, aplicaram-se nos canteiros 5 t/ha de esterco bovino seco e, em cobertura, $24 \mathrm{t} /$ ha de cama-de-aviário parceladas em duas aplicações, aos 30 e 60 dias após o transplantio. O controle de ervas espontâneas durante o ciclo foi efetuado por meio de capinas manuais. Os dois insetos pragas ocorridos, lagarta rosca (Agrotis ipsilon) e broca-da-couve (Hellula phitidealis), foram controlados com pulverizações foliares semanais, usando a formulação contendo Bacillus thuringiensis.

A colheita do rabanete, no primeiro ano de cultivo, foi realizada aos 26 dias após a semeadura, e no segundo ano, aos 21 dias. O ponto de colheita foi quando as raízes tuberosas apresentavam diâmetro dentro do padrão normalmente comercializado na CEASA-RJ (2003). O repolho foi colhido aos 89 dias após o transplantio, no primeiro ano, e após 96 dias, no segundo ano, épocas em que a maioria das "cabeças" havia atingido o grau de compacidade e de desenvolvimento desejados.

As características avaliadas da cultura do repolho foram produção de massa fresca da parte aérea das plantas, massa e diâmetros, vertical e horizontal, da "cabeça". Para a cultura do rabanete, avaliaram-se a produção de massa fresca da planta inteira, massa e diâmetro das raízes. Os teores de N, P, K, Ca e $\mathrm{Mg}$ dos produtos exportados, "cabeças" e raízes, respectivamente, de repolho e rabanete, foram determinados seguindo os procedimentos referentes às análises de tecido vegetal segundo Bataglia et al. (1983) e Raij et al.(1996).

O rabanete é comercializado na forma de molhos de plantas inteiras na CEASA-RJ, assim foi considerada a massa fresca da planta inteira para se calcular a produtividade. Já do repolho são comercializadas as cabeças, por isso foi considerada a massa fresca de cabeças para se calcular a produtividade.

Os dados foram submetidos à análise de variância, aplicando-se o teste $\mathrm{F}$ (pd"0,05), utilizando o Sistema para Análises Estatísticas e Genéticas (SAEG) (RIBEIRO JÚNIOR, 2001). 
Tabela 1. Características agronômicas do rabanete em monocultivo ou consorciado com repolho em anos experimentais consecutivos. Seropédica (RJ), UFRRJ, 2000/2001.

\begin{tabular}{|c|c|c|c|}
\hline \multirow{2}{*}{ Modo de cultivo } & Massa fresca total & Massa fresca raiz & \multirow{2}{*}{$\begin{array}{l}\text { Diâmetro da raiz } \\
\text { (mm/planta) }\end{array}$} \\
\hline & \multicolumn{2}{|c|}{ (g/planta) } & \\
\hline & \multicolumn{3}{|c|}{ Ano $1-2000$} \\
\hline Monocultivo & $61,75 a^{1}$ & $37,65 \mathrm{a}$ & $34,70 \mathrm{a}$ \\
\hline Consórcio & $38,22 \mathrm{~b}$ & $21,20 \mathrm{~b}$ & $24,60 \mathrm{~b}$ \\
\hline \multirow[t]{2}{*}{$\mathrm{CV}(\%)$} & 19,00 & 22,00 & 5,00 \\
\hline & \multicolumn{3}{|c|}{ Ano 2 - 2001} \\
\hline Monocultivo & $41,40 a$ & $22,25 \mathrm{a}$ & $25,20 a$ \\
\hline Consórcio & $35,87 \mathrm{~b}$ & $19,01 \mathrm{~b}$ & $21,50 \mathrm{~b}$ \\
\hline $\mathrm{CV}(\%)$ & 15,00 & 23,00 & 11,00 \\
\hline
\end{tabular}

${ }^{1}$ Médias seguidas da mesma letra, nas colunas, em cada ano, não diferem entre si pelo teste $\mathrm{F}(\mathrm{p} \leq 0,05)$.

Tabela 2. Produtividade de "cabeças" de repolho e de raízes de rabanete, em monocultivo ou consorciados com o respectivo índice de equivalência de área nos anos 2000 e 2001. Seropédica (RJ), UFRRJ, 2000/2001.

\begin{tabular}{lcc}
\hline \multirow{2}{*}{ Modo de cultivo } & \multicolumn{2}{c}{ Produtividade (t/ha) } \\
\cline { 2 - 3 } & Ano 1 (2000) & Ano 2 (2001) \\
\hline Repolho monocultivo & $38,57 \mathrm{a}^{1}$ & $37,14 \mathrm{a}$ \\
Repolho consórcio & $33,88 \mathrm{a}$ & $33,14 \mathrm{a}$ \\
\hline CV (\%) & 20,00 & 24,00 \\
\hline Rabanete monocultivo & $30,12 \mathrm{a}$ & $17,80 \mathrm{a}$ \\
Rabanete consórcio & $16,96 \mathrm{~b}$ & $15,36 \mathrm{~b}$ \\
\hline CV (\%) & 23,00 & 19,00 \\
\hline Índice de Equivalência de Área (IEA) & 1,44 & 1,75 \\
\hline
\end{tabular}

${ }^{1}$ Médias seguidas da mesma letra, nas colunas, em cada ano, não diferem entre si pelo teste $\mathrm{F}(\mathrm{p} \leq 0,05)$.

Calculou-se o índice de equivalência de área (IEA), obtido a partir da relação entre a produtividade na área cultivada em consórcio e aquela em monocultivo (FAGERIA, 1989; VANDERMEER, 1990), usando a fórmula:

$$
\begin{gathered}
\text { IEA }=\frac{\text { prod. de rabanete em consórcio }}{\text { prod. de rabanete em monocultivo }} \\
+\frac{\text { prod.do repolho em consórcio }}{\text { prod.do repolho em monocultivo }}
\end{gathered}
$$

\section{RESULTADOS E DISCUSSÃO}

Não houve interação significativa entre o pré-cultivo com crotalária e os modos de cultivo (monocultivos ou consórcio), para todas as características avaliadas. O pré-cultivo com a leguminosa também não interferiu nas características agronômicas do repolho nem do rabanete. Isso pode ser atribuído aos altos teores de nutrientes disponíveis no solo, já que a área experimental tem sido con- tinuamente cultivada com hortaliças, que recebem quantidade considerável de fertilizantes orgânicos. Normalmente, o repolho se beneficia da adubação verde na forma de pré-cultivo, conforme demonstrado por Oliveira et al. (2003), que encontrou aumentos de $40 \%$ na produtividade dessa hortaliça após cultivo sobre a palhada da crotalária, quando comparada com a vegetação espontânea.

Nos dois anos experimentais, o repolho teve produção de massa fresca de parte aérea total $(1,90 \mathrm{~kg} /$ planta $)$, massa fresca de "cabeça" (1,26 kg/planta) diâmetro vertical $(13,06 \mathrm{~cm} /$ planta $)$, diâmetro horizontal $(15,87 \mathrm{~cm} /$ planta $) \mathrm{se}$ melhante em monocultivo e consorciado com rabanete. Assim, verifica-se que a inclusão do rabanete no sistema de consórcio não prejudicou consistentemente o desenvolvimento do repolho. Para o produtor, a renda extra com o rabanete viria antes do término do ciclo do repolho, praticamente sem onerar custos. As vantagens ora apontadas fo- ram reconhecidas por Sudo (1998), Sudo et al. (2001) e Paula (2003), também em cultivo orgânico na mesma área, porém, com outras hortaliças consorciadas (alface-cenoura, alface-rabanete e alface-cebola, respectivamente).

As características avaliadas do rabanete (Tabela 1) apresentaram valores menores no cultivo consorciado, mesmo tendo sido a semeadura realizada em épocas distintas nos diferentes anos experimentais. Logo, depreende-se que, dentro dos limites avaliados, a época de semeadura do rabanete em relação ao repolho, no manejo proposto, não evita o processo de competição. Esse tipo de resposta em relação ao rabanete também foi observado por Sudo et al. (2001) quando em consórcio com a alface.

$\mathrm{O}$ menor rendimento do rabanete está provavelmente associado à competição que naturalmente ocorre em cultivos onde associam-se diferentes espécies. De acordo com o "princípio da exclusão competitiva", descrito por Vandermeer (1990), quando duas espécies têm requerimentos distintos, competem entre si fracamente, sobrevivendo indefinidamente no mesmo ecossistema; porém, quando os requerimentos são similares, competem entre si fortemente, com uma delas tendendo a se extinguir em dado período de tempo. É importante salientar que apesar de o consórcio ter provocado impacto sobre o desempenho do rabanete, não inviabilizou a obtenção de raízes com padrão comercial, de acordo com o CEASA-RJ (2003).

A partir dos valores de produtividade do repolho e rabanete (Tabela 2), obtidos nos dois anos experimentais, foi calculado o IEA que, em valores médios alcançou 1,59. Isto significa que seria necessário um acréscimo de 59\% de área plantada (espaço físico) para se obter, com os monocultivos, produtividades totais equivalentes às alcançadas nos consórcios. Um consórcio é considerado eficiente quando o valor do IEA for superior a 1,00 (FAGERIA, 1989 e VANDERMEER, 1990), desde que o padrão comercial das culturas seja atingido. Os valores mais altos alcançados no IEA no $2^{\circ}$ ano experimental (Tabela 2) estão intimamente associados à menor produtividade do rabanete obtida no monocultivo nesse ano, 
Tabela 3. Exportação de nutrientes nas partes aéreas das plantas de repolho e nas raízes de rabanete, cultivadas sob manejo orgânico, em monocultivo ou consorciadas nos anos 2000 e 2001. Seropédica (RJ), UFRRJ, 2000/2001.

\begin{tabular}{|c|c|c|c|c|c|c|c|c|c|c|}
\hline \multirow{3}{*}{ Modo de cultivo } & \multicolumn{5}{|c|}{ Repolho } & \multicolumn{5}{|c|}{ Rabanete } \\
\hline & $\mathbf{N}$ & $\mathbf{P}$ & $\mathrm{K}$ & $\mathrm{Ca}$ & $\mathrm{Mg}$ & $\mathbf{N}$ & $\mathbf{P}$ & $\mathrm{K}$ & $\mathrm{Ca}$ & $\mathrm{Mg}$ \\
\hline & \multicolumn{10}{|c|}{ (kg/ha) } \\
\hline & \multicolumn{10}{|c|}{ Ano $1-2000$} \\
\hline Monocultivo & $66,78 a^{1}$ & 9,99 a & $123,03 \mathrm{a}$ & 20,04 a & $6,73 \mathrm{a}$ & 71,75 a & 12,49 a & 144,38 a & 21,46 a & $7,28 \mathrm{a}$ \\
\hline Consórcio & 68,29 a & $10,00 \mathrm{a}$ & $125,81 \mathrm{a}$ & 23,18 a & $7,68 \mathrm{a}$ & $33,58 \mathrm{~b}$ & $5,56 \mathrm{~b}$ & $64,85 \mathrm{~b}$ & $9,79 \mathrm{~b}$ & $3,66 \mathrm{~b}$ \\
\hline \multirow[t]{2}{*}{ CV (\%) } & 12,00 & 12,00 & 9,00 & 13,00 & 8,00 & 12,00 & 13,00 & 11,00 & 41,00 & 11,00 \\
\hline & \multicolumn{10}{|c|}{ Ano 2 - 2001} \\
\hline Monocultivo & $55,98 \mathrm{a}$ & $7,75 a$ & $102,19 a$ & $21,01 \mathrm{a}$ & $7,68 \mathrm{a}$ & $38,66 \mathrm{a}$ & $8,33 a$ & $65,53 a$ & $12,86 \mathrm{a}$ & $5,76 \mathrm{a}$ \\
\hline Consórcio & $68,79 a$ & $7,88 \mathrm{a}$ & 105,05 a & 27,74 a & $7,79 \mathrm{a}$ & $27,04 \mathrm{a}$ & $6,31 \mathrm{a}$ & 61,98 a & $9,12 \mathrm{a}$ & $4,22 \mathrm{a}$ \\
\hline$\overline{C V}(\%)$ & 7,00 & 13,00 & 7,00 & 12,00 & 10,00 & 29,00 & 13,00 & 25,00 & 17,00 & 10,00 \\
\hline
\end{tabular}

${ }^{1}$ Médias seguidas da mesma letra, nas colunas, em cada ano, não diferem entre si pelo teste $\mathrm{F}(\mathrm{p} \leq 0,05)$.

face, provavelmente, à antecipação da colheita, o que acarretou redução no diâmetro e na massa da raiz (Tabela 1 ). Pode-se notar também a estabilidade de produtividade alcançada com a cultura de repolho nos dois anos experimentais (Tabela 2), independentemente do modo de cultivo.

Nos consórcios, geralmente, se detecta alguma redução na produtividade das espécies associadas, o que evidencia a necessidade de estudos direcionados ao melhor entendimento dos mecanismos ecológicos específicos envolvidos nesse modo de cultivo (GLIESSMAN, 1990). Porém, considerando que o consórcio envolvendo as culturas de repolho e rabanete não interferiu no desempenho do repolho, visto ser essa a cultura considerada principal, evidencia-se que, do ponto de vista agronômico, esse modo de cultivo torna-se vantajoso, possibilitando, com a cultura intercalar de rabanete, obter-se produção adicional para uma dada área, além de otimizar práticas culturais tais como capina, irrigação e adubação.

$\mathrm{O}$ conceito de sustentabilidade, visto em sentido amplo, infere que qualquer sistema de produção agrícola deve gerar equilíbrio no balanço entre importação e exportação de nutrientes. Portanto, é fundamental que processos relacionados à perda de nutrientes sejam minimizados, por meio de modificações e adequações de práticas conservacionistas, de maneira a otimizar o aproveitamento dos nutrientes nos sistemas de produção, seja pelo aumento na eficiência de recuperação, seja reduzindo-se as quantidades aplicadas (GOUGH; HERRING, 1993). Neste sentido, os consórcios podem se tornar práticas agrícolas que favoreçam o maior aproveitamento dos nutrientes.

Ao se contrastar a exportação de N, $\mathrm{P}, \mathrm{K}, \mathrm{Ca}$ e $\mathrm{Mg}$ nos produtos colhidos (Tabela 3), no consórcio e respectivos monocultivos, nota-se que, no caso do repolho, as quantidades foram similares. No caso do rabanete, no primeiro ano, a exportação foi maior no monocultivo, devido, provavelmente, à maior produtividade (Tabela 2). Um outro benefício relevante do consórcio entre repolho e rabanete está associado à maior recuperação de nutrientes do solo por unidade de área, considerando o somatório das culturas, permitindo que balanços mais favoráveis entre a entrada, por meio das adubações, e exportações, via produtos, sejam alcançados.

Dessa forma pode-se concluir que o cultivo consorciado do repolho com rabanete foi adequado do ponto de vista agronômico, pois a presença do rabanete não prejudicou a produção do repolho, além de se apresentar como possibilidade concreta de gerar renda extra para o agricultor em uma mesma área física.

\section{AGRADECIMENTOS}

À Capes, CNPq, Embrapa Agrobiologia e UFRRJ pelo apoio com os recursos financeiros para realização do trabalho.

\section{LITERATURA CITADA}

BATAGLIA, O.C.; FURLANI, A.M.C.; TEIXEIRA, J.P.F.; GALLO, J.R. Métodos de análise química de plantas. Campinas/SP, IAC (Boletim Técnico n. $\left.{ }^{\circ} 78\right), 1983.32$ p.
CEASA-RJ, CENTRAIS DE ABASTECIMENTO DO ESTADO DO RIO DE JANEIRO S/A. Av. Brasil, 19.001, Irajá 21539-900 Rio de Janeiro-RJ. Disponível em: <htt:// www.ceasa.rj.gov.br>, fornecido por e-mail: ceasarj@ceasa.rj.gov.br 2003.

COSTA, M.B.B.; CAMPANHOLA, C.A. A agricultura alternativa no Estado de São Paulo. Jaguariúna-SP, Embrapa-CNPMA, (Série Documentos, $\mathrm{n}^{\circ}$ 07). 1997. $63 \mathrm{p}$.

EHLERS, E. Agricultura sustentável: origens e perspectivas de um novo paradigma. 2 ed. rev. ampl. Guaíba: Agropecuária, 1999, 157 p.

FAGERIA, N.K. Sistemas de cultivo consorciado. In: FAGERIA, N.K. (Ed) Solos tropicais e aspectos fisiológicos das culturas. Brasília: Embrapa-DPU, 1989. p.185-196.

GLIESSMAN, S.R. Researching the ecological basis for sustainable agriculture. In: GLIESSMAN, S.R. (Ed) Agroecology: researching the ecological basis for sustainable agriculture. Santa Cruz: University of California. 1990. p.3-10.

GONÇALVES, S.R. Consorciação de culturas técnicas de análises e estudos da distribuição. 1981. 217 f. (Tese mestrado) - UnB, Brasília.

GOUGH, L.P.; HERRING, J.R. Geologic research in support of sustainable agriculture. Agriculture, Ecosystems and Environment, v.46, p.55-68, 1993. HAAG, H.P.; MINAMI, K. Nutrição mineral de hortaliças. Marchas de absorção de nutrientes pela cultura do rabanete. In: HAAG, H.P.; MINAMI, K. (Coord.) Nutrição mineral em hortaliças. 2. ed. Campinas: Fundação Cargil, 1988, p.43-51. OLASANTAN, F.O.; EZUMAH, H.C.; LUCAS, E.O. Effects of intercropping with maize on the micro-environment, growth and yield of cassava. Agriculture, Ecosystems and Environment, v.57, p.149-158, 1996.

OLIVEIRA, F.L.; RIBAS, R.G.T.; JUNQUEIRA, R.M.; PADOVAN, M.P.; GUERRA, J.G.M.; ALMEIDA, D.L.; RIBEIRO, R.L.D. Uso do précultivo de Crotalaria juncea e de doses crescentes de cama de aviário na produção de repolho sob manejo orgânico. Agronomia, v.37, n.02, p.6066, 2003.

OLIVEIRA, F.L. Manejo orgânico da cultura do repolho (Brassica oleracea var. capitata): adubação orgânica, adubação verde e consorciação. 2001. 88 f. (Tese mestrado) - UFRRJ, Seropédica. 
PAULA, P.D. Desempenho de cultivares de cebola, sob manejo orgânico, no Estado do Rio de Janeiro. Seropédica, 2003. 79 f. (Tese mestrado) UFRRJ, Seropédica.

PIMENTEL, M.S. Dinâmica de parâmetros microbianos e do carbono orgânico do solo sob sistema orgânico de produção comparado com pasto e fragmento de mata secundária. 2001. 127 f. (Tese mestrado) - UFRRJ, Seropédica.

RAIJ, B.; CANTARELLA, H.; QUAGGIO, J.A.; FURLANI, A.M.C. Recomendação de adubação e calagem para o estado de São Paulo. 2. ed, Campinas: IAC e Fundação IAC, Boletim Técnico 100, 1996, 285 p.
RIBEIRO JÚNIOR, J.I. Análises estatísticas no SAEG. Viçosa: UFV, 2001. 301 p.:il

SUDO, A. Viabilidade agronômica de consórcios de olerícolas sob manejo orgânico. Seropédica, 1998. 131 f. (Tese mestrado) - UFRRJ, Seropédica.

SUDO, A.; OLIVERA, F.L.; GUERRA, J.G.M.; ALMEIDA, D.L.; RIBEIRO, R.L.D. Cultivo consorciado de alface e rabanete sob manejo orgânico. Seropédica/RJ: Embrapa Agrobiologia, Recomendação técnica, v.11, 2001, 4 p.
SWIFT, M.J.; ANDERSON, J.M. Biodiversity and ecosystem function in agricultural systems. In: SCHULZE. E.D.; MOONEY, H.A. (Eds). Biodiversity and ecosystems function. Berlin: Springer Verlag, 1994, p.15-41.

VANDERMEER, J.H. Intercropping. In: GLIESSMAN, S.R. (Ed.) Agroecology: researching the ecological basis for sustainable agriculture. 1990, p.481-516. 